\title{
Evaluation of the potential index model to predict habitat suitability of forest species: the potential distribution of mountain pine (Pinus uncinata) in the Iberian peninsula
}

\author{
Eduardo T. Mezquida • Agustín Rubio $\cdot$ \\ Otilio Sánchez-Palomares
}

\begin{abstract}
Characterization of the suitability or potentiality of a territory for forest tree species is an important source of information for forest planning and managing. In this study, we compared a relatively simple methodology to generate potential habitat distribution areas that has been traditionally used in Spain (the potential index model) with a statistical modelling approach (generalized linear model). We modelled the potential distribution of mountain pine (Pinus uncinata) in the Iberian peninsula as a working example. The potential index model generated a map of habitat suitability according to the values of an index of potentiality, whose distribution has usually divided into four categories based on quartiles (from optimum to low suitability). Considering all values of the index of potentiality as presences of mountain pine resulted in a low to moderate degree of agreement between the potential index model and the generalized linear model according to the kappa coefficient. Using the cut-off value of the index of potentiality that maximized the degree of agreement between both modelling approaches resulted in a substantial similarity between the maps of the predicted distribution of mountain pine. This cut-off value did lie in the upper-third quartile of the potential index distribution (high
\end{abstract}

suitability category), and roughly coincided with the upper 30th percentile. The use of statistical techniques, which have proved to be powerful and versatile for species distribution modelling, is recommended. However, the potential index model, together with the adjustments proposed here, could be a reasonably simple methodology to predict the potential distribution of forest tree species that forest managers should take into account when evaluating forestation and afforestation projects.

Keywords Forest managers - Habitat suitability . Potential distribution maps - Potential index model . Statistical modelling

\section{Introduction}

Predicting the potential distribution areas of species is an important issue in several disciplines such as biology, ecology and biogeography (Guisan and Zimmermann 2000; Guisan and Thuiller 2005). Modelling techniques to predict habitat suitability for particular species are being increasingly used in developing strategies for conservation, planning and forest management (Araújo et al. 2002; Edenius and Mikusinski 2006). For example, timber productivity has been traditionally one of the main goals in forest management, and different measures to assess the quality of a territory for a particular tree species and wood productivity have been used (e.g. site index, site quality, timber yield; Tyler et al. 1996; Corona et al. 1998; Chen et al. 1998). However, besides productivity, present reforestation and afforestation projects are growingly used for other purposes, such as combating desertification, forest restoration, carbon mitigation or conserving biodiversity. Therefore, forest managers need reliable and accurate 
information on the suitability of an habitat for native tree species to make management decisions.

In Spain. studies aimed to characterize the suitability of habitats for tree species started during the 1960 s (e.g. Nicolás and Gandullo 1967, 1969: Gandullo 1972; Gandullo et al. 1974). Several climatic, physiographic and soil (if available) variables were used to characterize and quantify the suitability of a territory for selected forest species (Gandullo and Sánchez Palomares 1994; Rubio et al. 2002). Methodology used has not substantially changed, although some modifications and improvements have been included (SánchezPalomares et al. 2004; Rubio and Sánchez-Palomares 2006). This methodology is relatively simple when compared to the wide range of statistical approaches currently used in predictive habitat modelling (Guisan and Zimmermann 2000: Anderson et al. 2003: Benito-Garzón et al. 2006). However. statistical modelling techniques are not always accessible to forest managers, and one of the aims of the above-mentioned studies conducted in Spain was to develop a simple, easy-touse methodology readily accessible to forest managers (Rubio and Sánchez-Palomares 2006).

Here, we compared the methodology developed and commonly used in Spain to predict potential distribution areas of tree species based on habitat suitability indicator models (Rubio et al. 2002: Sánchez-Palomares et al. 2004; Rubio and Sánchez-Palomares 2006) with one of the statistical models regularly used to model habitat suitability maps (Guisan and Zimmermann). We used the distribution of mountain pine (Pinus uncinata) in the lberian peninsula as a working example for the comparison. The distribution area of mountain pine is restricted to the south, southcentral European mountain systems, mainly the Pyrenees and the western and central part of the Alps. The mountain pine is a high-altitude pine that usually constitutes the main component of the upper forest limits and tree lines. Our specific goals were (a) to model the potential distribution of mountain pine in the Iberian peninsula following the methodology of Rubio and Sánchez-Palomares (2006), (b) to model the potential distribution of this pine species in the Iberian peninsula using a generalized linear model, (c) to compare the performance of both modelling approaches and (d) to propose a cut-off point to better calibrate the methodology of Rubio and Sánchez-Palomares (2006).

\section{Methods}

Study site

The study area was restricted to the Spanish provinces where natural mountain pine forests occur, excluding those resulting from reforestation out of its natural distribution. The main distribution area of mountain pine in the Iberian peninsula is located in the Pyrenees (NE Spain: Barcelona, Girona, Lleida, Huesca, and Navarra provinces), and also two small isolated areas are sited in the Iberian mountain range (Teruel and Soria provinces).

Data set

We have used the database of the second and third Spanish National Forest Inventory (NFI). This database includes 73.517 circular sampling plots regularly distributed at $1 \mathrm{~km}$ intervals over forested areas. All trees with diameter at breast height $(\mathrm{DBH})>7.5 \mathrm{~cm}$ were recorded in circular plots of varying radius $(5,10,15$ and $25 \mathrm{~m}$ ) according to their DBH (larger than $7.5,12.5,22.5$ and $42.5 \mathrm{~cm}$. respectively DGCONA 1998). After excluding plots in likely reforested areas, we selected 977 plots from the NFI database where mountain pine was present.

\section{Environmental variables}

A set of topographic and climatic variables were used as predictors. Topographic variables included altinıde in meters, and slope gradient in degrees and insolation index calculated as a function of slope and aspect (Gandullo 1974). A 25-m resolution Digital Elevation Model (DEM) was used to generate these variables for each plot. The climatic parameters considered were: annual, spring. summer, autumn and winter precipitation in millimeters. annual average temperature and temperature fluctuation in degrees centigrade, length of drought duration measured as the number of months in which precipitation is less than twice the temperature. sum of the 12 monthly potential evapotranspirations (Thornthwaite 1948), and annual moisture surplus and annual moisture deficit (Thornthwaite and Mather 1957) in millimeters. We used the models developed by Sánchez-Palomares et al. (1999) to estimate these climatic parameters for each plot. This models include information from 2,605 weather stations, covering the period from 1974 to 1990 , and estimate climatic parameters as a function of altitude. geographical position (coordinates $x$ and $y$ of the Universal Transversal Mercator projection. Hayford ellipsoid), and hydrographical basin or sub-basin in which the plot is located.

Potential habitat distribution models

\section{Potential index model}

In the present work, we name 'potential index model' to the modelling approach developed by Sánchez-Palomares et al. (2004) and Rubio and Sánchez-Palomares (2006) to model species distribution areas. A detailed description of the methodology can be found in Rubio and Sánchez-Palomares (2006). In summary, several values and threshold 
values are calculated (such us absolute minimum and maximum. mean, the 10th percentile on both tails of the distribution) for each parameter. Then. the central and marginal habitats are defined on the basis of the calculated values for each parameter. To calculate an index of how suitable a particular site is for a species, a 'partial potential index' is calculated for each parameter using different estimations according to the value of the parameter (i.e. if it falls on the defined central or marginal habitats) for the given site (see equations in Rubio and Sánchez-Palomares 2006). The final potential index for a given site is calculated as the product of the partial indexes estimated for each parameter.

\section{Statistical model}

Different statistical techniques can be used to model potential distribution areas (Guisan and Zimmermann 2000 ). For the purpose of comparing the potential index model to an statistical model. we used generalized linear models, which are based on presence/absence data and have been extensively used in predictive modelling (Guisan et al. 1998: Thuiller et al. 2003a: Brotons et al. 2004). We used 977 plots extracted from the NFI database where mountain pine was present as presence data. For absences, we generated a grid similar to the NFI protocol $(1 \mathrm{~km}$ grid). Mountain pine does not occur at low altitudes (range $857-2,519 \mathrm{~m}$ for the $977 \mathrm{NFI}$ plots). Hence, to avoid selecting points at low elevations (e.g. Ebro basin, coastal areas) and use points with topographic and climatic characteristics more similar to presences (that will better predict presences under our modelling approach; Guisan et al. 1998), we discarded points below $700 \mathrm{~m}$ in elevation. From the remaining points, we randomly selected 977 points to balance presences and absences (Manel et al. 2001). With the binary data of mountain pine presences and absences. we applied generalized linear regression techniques with binomial error distribution and a logistic link (GLM).

The original dataset (977 presences and 977 absences) were split into two parts for model calibration and evaluation (Guisan and Zimmermann 2000). The model was calibrated using $2 / 3$ of the original plots and afterwards evaluated using the remaining $1 / 3$ plots. From the set of 14 environmental variables included as potential predictors, we eliminated annual precipitation because it was highly correlated with seasonal precipitations, and length of drought duration because it was nil for all plots. We did not apply techniques to simplify the model and used the saturated model (including the 12 predictor variables) instead. In this way. we compared the potential index model, which combines all predictor variables, to a GLM that also includes all environmental predictors.
The habitat model developed with the calibration dataset was evaluated on the evaluation dataset using cross-validation. Predicted values from the GLM have a value between 0 and 1 , and thus to select the threshold probability that best reduces the adjusted probability values to 0 and 1, we used Cohen's kappa (Cohen 1960). The calculation of kappa coefficient requires the derivation of a confusion matrix that identifies true positive. false positive, false negative and true negative cases predicted by the model. Kappa values range from 0 to $I$ and, in general. values of $0.0-0.4$ indicate slight to fair model performance, values of $0.4-0.6$ moderate, $0.6-0.8$ substantial and 0.8-1 almost perfect (Landis and Koch 1977; Manel et al. 2001).

\section{Potential habitat distribution maps}

We derived potential distribution maps of mountain pine by applying the two models over the whole studied region. The same set of environmental variables used to construct the models was calculated for each grid cell of the $25-\mathrm{m}$ resolution DEM. For the potential index model, we applied the calculated potential index formula to each grid cell and derived a potential distribution map by including the data into a Geographic Information System (GIS; ArcGis ver. 9.2. ESRI lnc., Redlands, CA). For the GLM, the potential distribution map is generated in a GIS by applying the regression equation to every cell of the grid. The obtained values are at the scale of the linear predictor (LP), so we applied the inverse logistic transformation

$p(y)=\exp (\mathbf{L P}) /(1+\exp (\mathbf{L P}))$

to get probability values between 0 and 1 for each cell of the grid (Guisan et al. 1998).

\section{Comparison between the two models}

The potential distribution map resulting from the potential index model shows areas where the considered species is absent and those where it is present. For presences, the potentiality or suitability of a given area is indicated by the value of the potential index. The range of values that this index can take has been usually divided into four categories (optimum, high, medium or low potentiality) for practical purposes (Rubio and Sánchez-Palomares 2006). In order to compare the potential distributions map derived from the potential index and the GLM models, we first considered any value of the potential index as presence. Then, we calculated the kappa coefficient between both maps. After this raw comparison, we sought for the value of the potential index that maximized the degree of agreement between both models using kappa coefficient. 


\section{Results}

Predictions of models

The mean and upper and lower 10th percentiles calculated for each environmental variable from the range of values on the NFI plots where mountain pine was present (Table 1), defined the central and marginal habitats for the calculation of habitat potentiality or suitability in the potential index model. After applying the potential index formula to the whole studied region, we derived a potential distribution map of absences and presences ranked according to the values of the potential index (Fig. 1). For this tree species and dataset, values of the potential index ranged from 2.64 to 3.98 . Usual classification based on quartiles would result in four categories of potentiality or suitability: optimum (from 3.79 to 3.98 ), high (3.68 to 3.79 ), medium (3.57 to 3.68 ) and low (2.64 to 3.57 ).

Regression coefficients and summary statistics resulting from fitting a GLM using all environmental variables as predictors are shown in Table 2. The best kappa coefficient obtained with the evaluation dataset was 0.76 , which corresponded to a threshold probability of 0.6 that was used to generate the final presence/absence map (Fig. 2). This value of the kappa coefficient indicated a reasonably good model performance.

Comparison of mountain pine distribution between models

The degree of agreement between the potential index model considering any index value as presences (Fig. 1) and the GLM was low to moderate (kappa $=0.41$ ). The cut-off value of the index to derive a presence/absence map in the potential index model that maximized the degree of agreement between the two models was 3.74 (Fig. 3). Kappa coefficient using this threshold value was 0.69 . The 3.74 value of the potential index would lie in the upper medium quartile of the distribution, which corresponded to the high suitability category. Using this cut-off value, the potential distribution area of the mountain pine predicted by the potential index model would occupy $4.574 .8 \mathrm{~km}^{2}$. whereas the area predicted by the GLM would be somewhat lower $\left(3,873.8 \mathrm{~km}^{2}\right.$ : Figs. 2, 3).

\section{Discussion}

Our results showed that the performance of the GLM model was very good (according to kappa coefficient) at predicting presences and absences of mountain pine. Output of the potential index model is based on suitability categories, so considering all categories as presences resulted in low to moderate model performance. However, using a cut-off point that corresponded to the optimum and part of the high suitability categories, model performance increased and almost matched GLM model performance. The calculated cut-off point roughly coincided with the upper 30th percentile of the suitability distribution in the potential index model, so using these values as potential presences to derive a potential distribution map would improve the predictive performance of the potential index model.

Models based on habitat suitability for species are increasingly used by managers during planning, implementation and monitoring of forest, conservation or land

Table 1 Mean, minimum, maximum, and lower and upper loth percentile values calculated for each environmental parameter used as predictor

\begin{tabular}{|c|c|c|c|c|c|}
\hline Environmental parameter & $\begin{array}{l}\text { Absolute } \\
\text { minimum }\end{array}$ & $\begin{array}{l}\text { Lower 10th } \\
\text { percentile }\end{array}$ & Mean & $\begin{array}{l}\text { Upper } 10 \text { th } \\
\text { percentile }\end{array}$ & $\begin{array}{l}\text { Absolute } \\
\text { maximum }\end{array}$ \\
\hline Altitude (m) & 857 & 1,448 & 1,781 & 2,094 & 2,519 \\
\hline Slope (deg) & 0.0 & 11.3 & 24.7 & 38.8 & 57.3 \\
\hline Insolation index & 0.00 & 0.37 & 0.81 & 1.22 & 1.41 \\
\hline Spring precipitation (mm) & 215 & 240 & 303 & 358 & 755 \\
\hline Summer precipitation (mm) & 196 & 266 & 320 & 369 & 530 \\
\hline Autumn precipitation (mm) & 183 & 220 & 309 & 389 & 898 \\
\hline Winter precipitation (mm) & 100 & 131 & 208 & 282 & 830 \\
\hline Annual average temperature $\left({ }^{\circ} \mathrm{C}\right)$ & 2.7 & 4.4 & 6.1 & 7.9 & 11.2 \\
\hline Temperature fluctuation $\left({ }^{\circ} \mathrm{C}\right)$ & 17.9 & 22.1 & 25.3 & 28.2 & 31.1 \\
\hline Potential evapotranspiration & 267 & 417 & 495 & 569 & 676 \\
\hline Annual moisture surplus (mm) & 231 & 375 & 665 & 952 & 2,569 \\
\hline Annual moisture deficit (mm) & 0 & 0 & 20 & 44 & 120 \\
\hline
\end{tabular}

These values were used to define the central and marginal mountain pine habitats for the calculation of an index of potentiality or suitability in the potential index model 
Fig. 1 Map of habitat potentiality or suitability for mountain pine in the Iberian peninsula derived from the potential index model

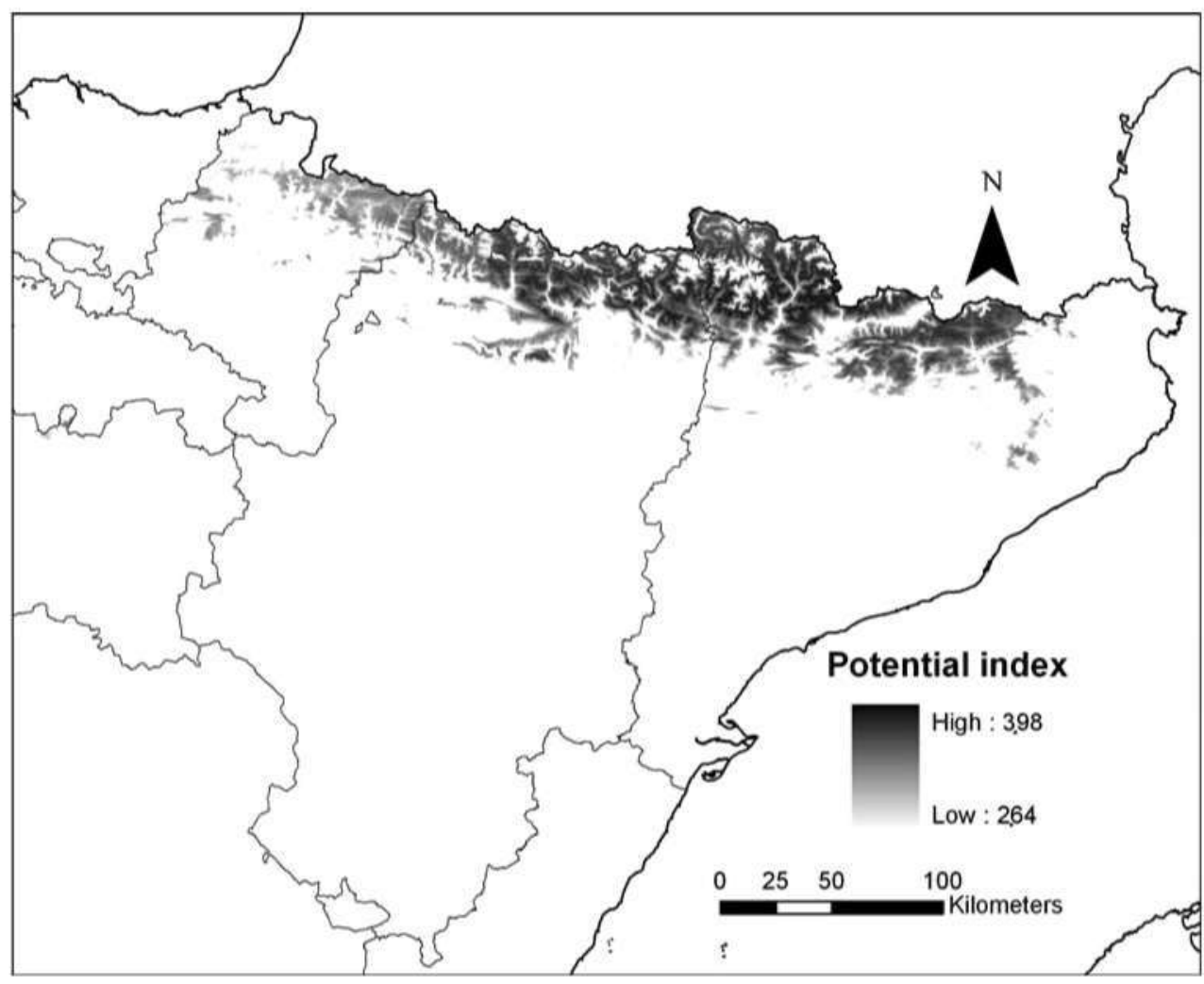

Table 2 Regression coefficients, standard errors, Wald statistics and their associated $P$ values for the generalized linear model with all environmental predictor variables

\begin{tabular}{lrrrr}
\hline Term & $\begin{array}{l}\text { Regression } \\
\text { coefficient }\end{array}$ & $\begin{array}{l}\text { Standard } \\
\text { error }\end{array}$ & $\begin{array}{l}\text { Wald } \\
\text { statistic }\end{array}$ & \multicolumn{1}{r}{$P$} \\
\hline Intercept & -54.087 & 8.151 & 44.04 & $<0.001$ \\
Altitude & 0.010 & 0.129 & 4.40 & 0.036 \\
Slope & -0.008 & 0.128 & 3.25 & 0.071 \\
Insolation index & -1.418 & 0.129 & 5.52 & 0.019 \\
Spring precipitation & -0.270 & 0.129 & 3.51 & 0.061 \\
Summer precipitation & -0.231 & 0.586 & 14.06 & $<0.001$ \\
Autumn precipitation & -0.304 & 0.087 & 23.84 & $<0.001$ \\
Winter precipitation & -0.241 & 0.129 & 7.05 & 0.008 \\
Annual average temperature & -2.196 & 0.129 & 4.31 & 0.038 \\
Temperature fluctuation & 0.426 & 0.129 & 4.75 & 0.029 \\
Potential evapotranspiration & 0.344 & 0.003 & 15.15 & $<0.001$ \\
Annual moisture surplus & 0.267 & 0.009 & 0.89 & 0.346 \\
Annual moisture deficit & -0.280 & 0.294 & 23.21 & $<0.001$ \\
\hline
\end{tabular}

use activities (Osborne et al. 2001; Gustafson et al. 2002; Holloway et al. 2003; Cabeza et al. 2004). For example, modern forest management is a complex, multi-faceted process that should focus on ensuring the sustainability of forest resources, ecosystems, and the social and economic structures that rely on them (Kohm and Franklin 1997; Erdle and Sullivan 1998). Therefore, forest managers require a wide range of reliable and up-to-date information during the decision-making process (Naesset 1997; Varma et al. 2000). Models that use information gathered at large spatial scales to predict habitat suitability of a given territory for different tree species are practical tools for forest managers when evaluating, for instance, reforestation or afforestation projects. However, habitat suitability models have increasingly used complex statistical techniques and GIS tools during the modelling approach (Manel et al. 1999; Guisan and Zimmermann 2000; Guisan et al. 2002) that are not always accessible to forest managers. Nevertheless, forest managers are encouraged by society to incorporate all these approaches into their management 
Fig. 2 Potential distribution map of mountain pine in the Iberian peninsula derived from the generalized linear model

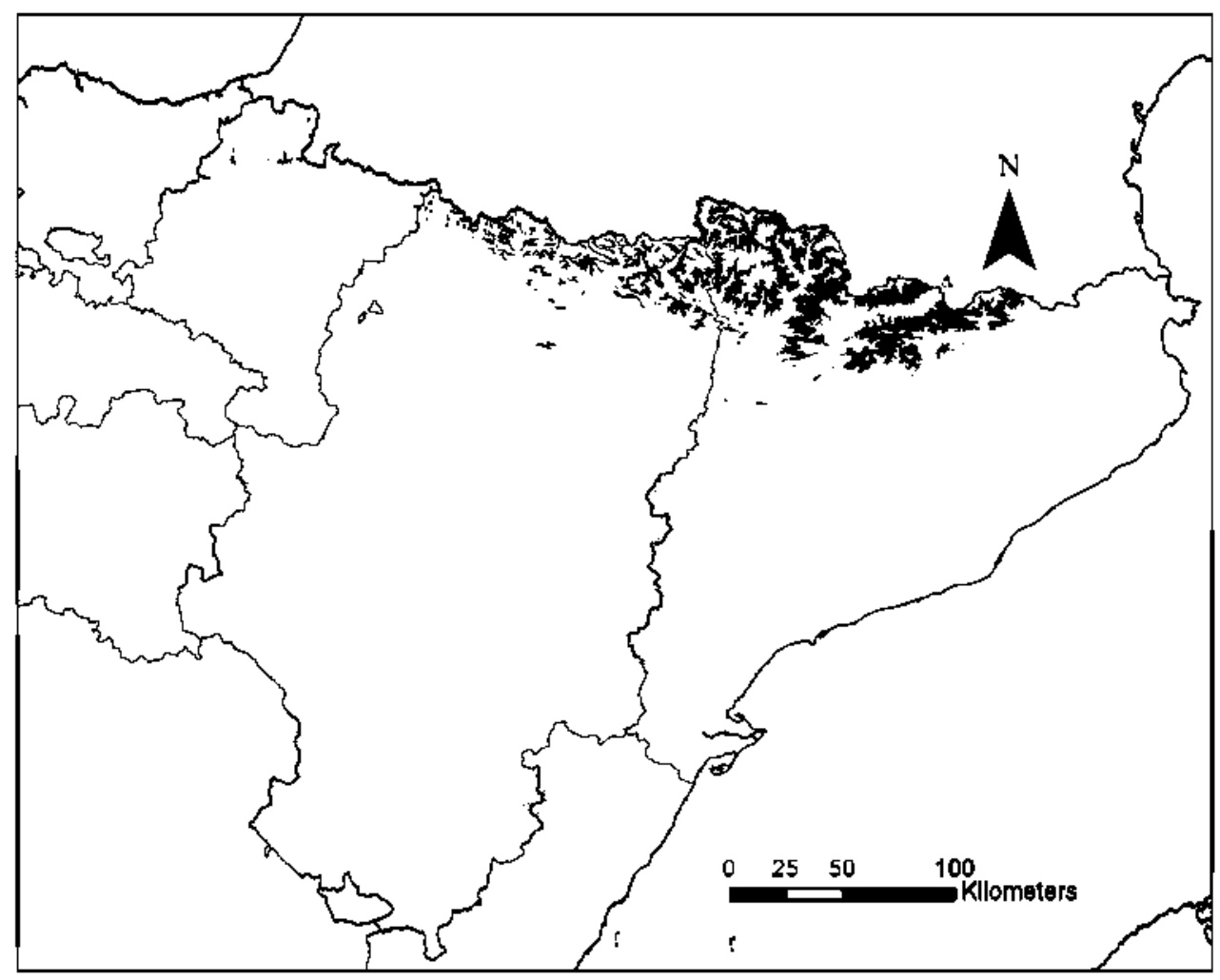

Fig. 3 Potential distribution map of mountain pine in the Iberian peninsula derived from the potential index model using the 3.74 cut-off value

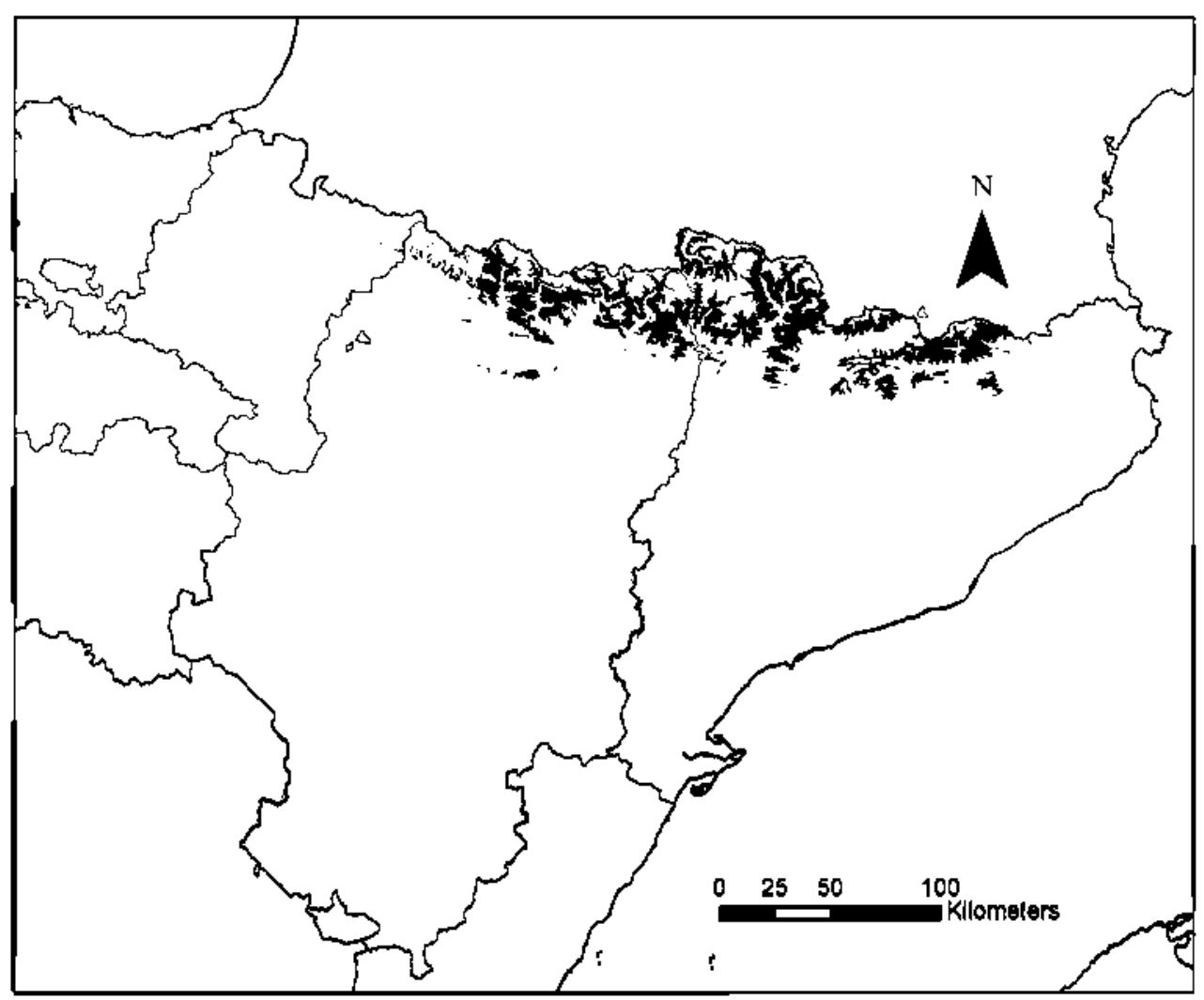


plans. The potential index modelling approach proposed by Rubio and Sánchez-Palomares (2006), together with the adjustments suggested in this work, could be a simpler, but still accurate, methodology.

The potential index modelling approach is thus a reasonably simple methodology to derive habitat suitability maps, although it has some limitations in the training and evaluation processes compared to statistical techniques. The potential index model uses all environmental variables to calculate partial potential indexes and combine them to calculate an index of potentiality or suitability. A map of habitat suitability is then derived with this calculations and GIS tools (Rubio and Sánchez-Palomares 2006). Therefore, predictions of the potential index model are a combination of all environmental variables (i.e. a full model). On the contrary, models using statistical techniques can take advantage of different simplification methods (e.g. stepwise regression. best subset regression. tree pruning) to avoid overfitting and to explore the set of predictor variables most correlated to the presence of a species. Model evaluation in the potential index methodology has been conducted in two ways: using a sample of the data set not included in the model calibration step, and contrasting predictions of the model with climax vegetation (Rubio and Sánchez-Palomares 2006). The first method checks if predictions of the model are concordant with observed data not used during model development. The second method is similar. but contrasts model predictions with proposed phytosociological vegetation series maps. In both cases. no statistical tools are used for model evaluation. and the second method depends on the availability of potential vegetation maps derived from phytosociological information. Model evaluation in statistical modelling approaches can be conducted using different techniques, depending on the type of data and the statistical model. For example. cross-validation, bootstrap, kappa coefficient, and receiver operating characteristic plots are some of the approaches widely used in predictive habitat modelling (Guisan and Zimmermann 2000).

\section{Conclusions}

We have developed a predictive model for the potential distribution of mountain pine in the lberian peninsula following two modelling approaches. One approach was the methodology that has been traditionally used in Spain to estimate the potential distribution of tree species (i.e. the potential index model). The other was a commonly used statistical model for presence/absence data (GLM). After adjusting the predictions of the potential index model (i.e. considering the upper 30 th percentile of the potential index distribution as presences), both approaches provided good results. The similarity between our predictive maps and maps of the potential distribution of mountain pine in Catalonia (NE Spain; also included in our analysis) generated using other statistical modelling approaches (Rouget et al. 2001; Thuiller et al. 2003b), further support our results.

Despite the limitations of the potential index model compared to the most powerful statistical techniques, this easy-to-implement methodology could be a reasonably simple tool that helps forest managers during decision making. Potential habitat distribution models could. for example. identify forest fragments with high suitability for the forest tree species to guide efforts in reducing fragmentation. Further, information for different tree species could aid in the delimitation of degraded ecotones or mixed forest where restoration programs would focus to increase diversity and complexity. These are just two examples of forest values that modern societies are demanding to forest managers.

Acknowledgments This work has been partially funded by project AGL2004-01941/FOR from the Spanish Ministry of Education and Science. Comments by three anonymous reviewers helped to improve an earlier version of the manuscript.

\section{References}

Anderson RP, Lew D, Peterson AT (2003) Evaluating predictive models of species distributions: criteria for selecting optimal models. Ecol Modell 162:211-232. doi:10.1016/\$0304-3800 (02)00349-6

Araújo MB, Williams PH. Fuller RJ (2002) Dynamics of extinction and the selection of nature reserves. Proc R Soc Lond B Biol Sci 269:1971-1980. doi: 10.1098/rspb.2002.2121

Benito-Garzón M. Blazek R, Neteler M. Sánchez de Dios R, Sainz Ollero H. Furlanello C (2006) Predicting habitat suitability with machine learning models: the potential area of Pinus sylvestris L. in the Iberian Peninsula. Ecol Modell 197:383-393. doi: 10.1016/j.ecolmodel.2006.03.015

Brotons L. Thuiller W, Araújo MB, Hirzel AH (2004) Presenceabsence versus presence-only modelling methods for predicting bird habitat suitability. Ecography 27:437-448, doi:10,1111/ j.0906-7590.2004.03764.x

Cabeza M. Araújo MB. Wilson RJ、Thomas CD, Cowley MJR. Moilanen A (2004) Combining probabilities of occurrence with spatial reserve design. J Appl Ecol 41:252-262. doi:10.1111/ j.0021-8901.2004.00905.x

Chen HYH, Klinka K. Kabzems RD (1998) Site index, site quality, and foliar nutrients of trembling aspen: relationships and predictions. Can J Res 28:1743-1755. doi:10.1139/cjfr-28-121743

Cohen J (1960) A coefficient of agreement for nominal scales. Educ Psychol Meas 20:37-46. doi: $10.1177 / 001316446002000104$

Corona P, Scotti R, Tarchiani N (1998) Relationship between environmental factors and site index in Douglas-fir plantations in central Italy. For Ecol Manag 110:195-207

DGCONA (1998) Segundo Inventario Forestal Nacional 1986-1996. Dirección General de Conservación de la Naturaleza, Madrid

Edenius L, Mikusinski G (2006) Utility of habitat suitability models as biodiversity assessment tools in forest management. Scand J For Res 21:62-72. doi: $10.1080 / 14004080500486989$ 
Erdle T, Sullivan M (1998) Forest management design for contemporary forestry. For Chron 74:83-90

Gandullo JM (1972) Ecología de los pinares españoles: III Pinus halepensis Mill. INIA, Madrid

Gandullo JM (1974) Ensayo de evaluación cuantitativa de la insolación en función de la orientación y de la pendiente del terreno. Inst Nac Investig Agrar Ser Recur Nat 1:95-107

Gandullo JM. Sánchez Palomares O (1994) Estaciones ecológicas de los pinares españoles. ICONA, Madrid

Gandullo JM. González Alonso S, Sánchez Palomares O (1974) Ecología de los pinares españoles: IV Pinus radiata D. Don. INIA, Madrid

Guisan A, Thuiller W (2005) Predicting species distribution: offering more than simple habitat models. Ecol Lett 8:993-1009. doi: $10.1111 / \mathrm{j} .1461-0248.2005 .00792 . x$

Guisan A. Zimmermann NE (2000) Predictive habitat distribution models in ecology. Ecol Modell 135:147-186. doi:10.1016/ S0304-3800(00)00354-9

Guisan A, Theurillat J-P. Kienast F (1998) Predicting the potential distribution of plant species in an alpine environment. J Veg Sci 9:65-74. doi: $10.2307 / 3237224$

Guisan A, Edwards TC. Hastie T (2002) Generalized linear and generalized additive models in studies of species distributions: setting the scene. Ecol Modell 157:89-100. doi:10.1016/S0304$3800(02) 00204-1$

Gustafson EJ, Lietz SM, Wright JL (2002) Predicting the spatial distribution of aspen growth potential in the upper Great Lakes region. For Sci 49:499-508

Holloway GJ, Griffiths GH, Richardson P (2003) Conservation strategy maps: a tool to facilitate biodiversity action planning illustrated using the heath fritillary butterfly. J Appl Ecol 40:413-422

Kohm KA, Franklin JF (1997) Creating a forestry for the 21st century, Island Press, Washington DC

Landis JR, Koch GG (1977) The measurements of observer agreement for categorical data. Biometrics 33:159-174. doi:10.2307/ 2529310

Manel S, Dias J-M. Ormerod SJ (1999) Comparing discriminant analysis, neural networks and logistic regression for predicting species distributions: a case study with a Himalayan river bird. Ecol Modell 120:337-347. doi: 10.1016/\$0304-3800(99)00113-1

Manel S, Williams HC, Ormerod SJ (200l) Evaluating presenceabsence models in ecology: the need to account for prevalence. J Appl Ecol 38:921-931. doi: 10.1046/j.1365-2664.2001.00647.x

Naesset E (1997) Geographical information systems in long-term forest management and planning with special reference to preservation of biological diversity: a review. For Ecol Manag 93:121-136

Nícolás A. Gandullo JM (1967) Ecología de los pinares españoles: Pinus pinaster Ait. IFIE, Madrid

Nicolás A, Gandullo JM (1969) Ecología de los pinares españoles: II Pinus sylvestris L. IFIE, Madrid

Osborne P, Alonso J, Bryant R (2001) Modelling landscape-scale habitat use using GIS and remote sensing: a case study with great bustards. J Appl Ecol 38:458-471. doi:10.1046/j.1365-2664. 2001.00604.x

Rouget M. Richardson DM. Lavorel S, Vayreda J, Gracia C, Milton SJ (2001) Determinants of distribution of six Pinus species in Catalonia, Spain. J Veg Sci 12:491-502. doi:10.2307/3237001

Rubio A, Sánchez-Palomares O (2006) Physiographic and climatic potential areas for Fagus sylvatica based on habitat suitability indicator models. Forestry 79:439-451. doi:10.1093/forestry/ cpl025

Rubio A, Sánchez-Palomares O, Gómez V, Graña D, Elena R, Blanco A (2002) Autoecología de los castañares de Castilla (España). Invest Agrar Sist Recur For 11:373-393

Sánchez-Palomares O, Sánchez F, Carretero MP (1999) Modelos y cartografía de estimaciones climáticas termopluviométricas para la España peninsular. INIA, Madrid

Sánchez-Palomares O, Rubio A, Blanco A (2004) Definición y cartografía de las áreas potenciales fisiogrático-climáticas de hayedo en España. Investig Agrar Sist Recur For S, pp 13-62

Thornthwaite CW (1948) An approach toward a rational classification of climate. Geogr Rev 38:55-94. doi: 10.2307/210739

Thomthwaite CW, Mather JR (1957) Instnctions and tables for computing potential evapotranspiration and the water balances. Climatology 10:185-311

Thuiller W. Araújo MB. Lavorel S (2003a) Generalized models versus classification tree analysis: a comparative study for predicting spatial distributions of plant species at different scales. J Veg Sci 14:669-680. doi:10.1658/1100-9233(2003)014 [0669:GMVCTA] 2.0.CO;2

Thuiller W, Vaydera J, Pino J, Sabaté S, Lavorel S, Gracia C (2003b) Large-scale environmental correlates of forest tree distributions in Catalonia (NE Spain). Glob Ecol Biogeogr 12:313-325. doi: 10.1046/j.1466-822X.2003.00033.x

Tyler AL, MacMillan DC, Dutch J (1996) Models to predict the general yield class of Douglas-fir Japanese larch and Scots pine on better quality land in Scotland. Forestry 69:13-24. doi: 10.1093 /forestry/69.1.13

Varma VK, Ferguson I, Wild I (2000) Decision support system for the sustainable forest management. For Ecol Manag 128:49-55 